APPROVED FOR PUBLIC RELEASE

C/ORNL99-0553

\author{
CRADA Final Report \\ for
}

CRADA Number ORNL99-0553

\title{
ADVANCED MICROCHARACTERIZATION OF NICKEL-BASE SUPERALLOYS
}

I.M. Anderson and M.K. Miller

Oak Ridge National Laboratory

L.M. Pike and D.L. Klarstrom

Haynes International, Incorporated

February 2000

Prepared by the

Oak Ridge National Laboratory

Oak Ridge, Tennessee 37831

managed by

Lockheed Martin Energy Research Corporation

for the

U.S. Department of Energy

under contract DE-AC05-96OR22464

This work was performed at the SHaRE User Facility, Oak Ridge National Laboratory, and was supported through a CRADA with Haynes International, Incorporated, Kokomo, Indiana, sponsored by the Laboratory Technology Research Program, Office of Science, U.S. Department of Energy, under contract DE-AC05-96OR22464 with Lockheed Martin Energy Research Corporation. 


\section{Contents}

$\begin{array}{ll}\text { ABSTRACT } & 3\end{array}$

STATEMENT OF THE OBJECTIVES 4

BENEFITS TO THE FUNDING DOE OFFICE'S MISSION 4

TECHNICAL DISCUSSION OF WORK PERFORMED BY ALL PARTIES 4

INVENTIONS (MADE OR REPORTED)

$\begin{array}{ll}\text { COMMERCIALIZATION POSSIBILITIES } & 7\end{array}$

$\begin{array}{ll}\text { PLANS FOR FUTURE COLLABORATION } & 7\end{array}$

$\begin{array}{ll}\text { CONCLUSIONS } & 8\end{array}$

$\begin{array}{ll}\text { DISTRIBUTION } & 9\end{array}$ 
Advanced Microcharacterization of Nickel-Base Superalloys

\author{
CRADA No. ORNL99-0553 \\ between \\ Haynes International, Incorporated \\ and \\ Oak Ridge National Laboratory
}

\begin{abstract}
$\underline{\text { Abstract }}$
The purpose of this project was to characterize the microstructural and microchemical effects of a process revision on HAYNES® $242^{\mathrm{TM}}$, a polycrystalline Ni-base superalloy used principally for high temperature applications, such as seal and containment rings in gas turbine engines. The process revision from the current one-step heat treating cycle to a two-step heat treatment would result in savings of energy and ultimately cost to the consumer. However, the proposed process revision could give rise to unforeseen microstructural modifications, such as a change in the size distribution of the ordered particles responsible for alloy strength or the formation of additional phases, which could affect alloy properties and hence performance. Advanced microcharacterization methods that allow images of the microstructure to be acquired at length scales from one micrometer down to the atomic level were used to reveal the effect of the process revision on alloy microstructure. Energy filtered imaging was used to characterize the size distribution and morphology of ordered precipitates and other phases, as well as the partitioning behavior of major elements (Ni, Mo, Cr) among these phases. The compositions of individual ordered particles, including fine-scale compositional variations at precipitate-matrix interfaces, and solute segregation behavior at grain boundaries were characterized at the atomic level by atom probe tomography. The atomic site distributions of selected elements in the ordered precipitates were characterized by atom-location by channeling-enhanced microanalysis (ALCHEMI). The results of these advanced microcharacterization methods were correlated with mechanical testing of similar alloys to address structure-property relationships.
\end{abstract}

This work was performed at the SHaRE User Facility, Oak Ridge National Laboratory, and was supported through a CRADA with Haynes International, Incorporated, Kokomo, Indiana, sponsored by the Laboratory Technology Research Program, Office of Science, U.S. Department of Energy, under contract DE-AC05-96OR22464 with Lockheed Martin Energy Research Corporation. 


\section{Statement of the Objectives}

The objective of this CRADA is to characterize the microstructural and microchemical changes resulting from a process revision on Haynes 242, so that the consequences of the process revision on alloy properties can be assessed, and so that the process revision or some modification of it can be adopted. The process revision would allow a shorter heat treating cycle, resulting in higher energy efficiency and lower cost to the consumer.

\section{Benefits to the Funding DOE Office's Mission}

This CRADA is funded by the DOE Office of Science through the Laboratory Technology Research Program. This CRADA provides benefits to the Office of Science's mission in the areas of Energy and Fundamental Science.

In the area of Energy, the adoption of the revised heat treatment process would result in lower energy consumption for the fabrication of the alloys, since the revised process leads to a substantial reduction of time at temperature.

In the area of Fundamental Science, this study helps to delineate several of the fundamental microstructural and microchemical issues for these superalloys, including phase equilibria, the distribution and morphology of phases in the microstructure, the partitioning of elements in the ordered particles responsible for alloy properties, and the interfacial segregation behavior. Nickel-base superalloys continue to be the material of choice for a variety of high-temperature applications critical to DOE missions, such as gas turbines. The results of this study will help to delineate the fundamental science of this superalloy system.

\section{Technical Discussion of Work Performed by All Parties}

\section{Fabrication of Alloys}

Haynes International, Incorporated provided two series of alloys in support of this CRADA: an air-melted production heat (I) and a vacuum-melted research heat (II), the two alloys differing slightly in composition. The solutionizing heat treatment was identical for each alloy, namely $1950^{\circ} \mathrm{F}$ for 0.5 hours, followed by water quenching. Each alloy was subjected to four heat treatments, which are summarized in Table 1.

Note that heat treatment A is the currently used one-step heat treatment for these alloys. Heat treatment $\mathrm{C}$ is the proposed two-step process; the additional heat treatment step at the intermediate temperature $\left(1300^{\circ} \mathrm{F}\right)$ allows the processing time at $1200^{\circ} \mathrm{F}$ to be reduced by a factor of three. Heat treatment $\mathrm{B}$ is a control to allow the evaluation of the microstructural evolution at each stage of the two-step heat treatment. Heat treatment D was designed to study the kinetics of additional phases above the solvus temperature of the ordered $\mathrm{Ni}_{2}(\mathrm{Mo}, \mathrm{Cr})$ phase responsible for alloy strength. One addition alloy was provided: an overaged alloy from the production heat (I), aged 24,000 hours at $1200^{\circ} \mathrm{F}$. 
This alloy was designed to provide a control alloy for ALCHEMI studies, since the long ageing treatment would allow a relatively high degree of order in the $\mathrm{Ni}_{2}(\mathrm{Mo}, \mathrm{Cr})$ particles.

Table 1. Heat treatment cycles for alloys. The alloys were air quenched after each isothermal treatment.

\begin{tabular}{|l|l|l|l|l|}
\hline Heat treatment & Temperature & Time at Temp. & Temperature & Time at Temp. \\
\hline A & & & $1200^{\circ} \mathrm{F}$ & $48 \mathrm{~h}$ \\
\hline $\mathrm{B}$ & $1300^{\circ} \mathrm{F}$ & $16 \mathrm{~h}$ & & \\
\hline $\mathrm{C}$ & $1300^{\circ} \mathrm{F}$ & $16 \mathrm{~h}$ & $1200^{\circ} \mathrm{F}$ & $16 \mathrm{~h}$ \\
\hline $\mathrm{D}$ & $1600^{\circ} \mathrm{F}$ & $4 \mathrm{~h}$ & $1200^{\circ} \mathrm{F}$ & $48 \mathrm{~h}$ \\
\hline
\end{tabular}

\section{Energy-filtered imaging}

Jump-ratio maps of the major elements (nickel, molybdenum and chromium) were used to characterize the size distribution of the ordered $\mathrm{Ni}_{2}(\mathrm{Mo}, \mathrm{Cr})$ particles in all alloys. All particles were roughly lenticular in shape, with an aspect ratio of approximately 8:5:1 in the major, intermediate and minor dimensions. These studies indicated a monomodal size distribution of these particles in all alloys, but that the particles were several times larger in alloys with heat treatments $\mathrm{B}$ and $\mathrm{C}$ than those with heat treatments $\mathrm{A}$ and D. For example, the ordered particles in alloys I-A and I-C were $\sim 25 \mathrm{~nm}$ and $\sim 150 \mathrm{~nm}$ in the major dimension. In short, the size of the ordered particles depended upon the highest (or first) temperature below the solvus to which the alloys were subjected. No significant difference in the microstructure was observed between specimens subjected to heat treatments B and C. In particular, the nucleation of smaller ordered particles during the second phase of the heat treatment was not observed.

The jump-ratio images also indicated the elemental partitioning between the ordered particles and the matrix phases. These images showed that the particles were substantially enriched in molybdenum, and depleted in nickel, relative to the matrix. In the jump-ratio images of the chromium, the ordered particles were always darker than the surrounding matrix, but the contrast was weak, and this contrast may have arisen from the higher background level (arising from the higher molybdenum concentration) in the particles relative to the matrix. Corresponding elemental maps of the chromium showed no significant difference in contrast between the particles and matrix.

Jump-ratio images were also acquired to characterize grain boundary segregation. Images acquired in the vicinity of a grain boundary indicated an enrichment of molybdenum, and a depletion of nickel, at the grain boundary. Jump ratio images were also formed to characterize the boron concentration. Boron was also found to segregate to the grain boundaries in these materials. No contrast difference was observed between the ordered particles and the matrix in the boron maps.

\section{Atom probe tomography}

Atom probe tomography studies of the morphologies and size distributions of the order precipitates yielded results consistent with those of the energy-filtered imaging characterization. In particular, a monomodal distribution of precipitates was observed in 
all alloys and no finer secondary precipitates were observed to form during the second step of the two-step heat treatment.

The partitioning of major elements between the matrix and the ordered precipitates was found to be consistent with the partitioning observed by energy-filtered imaging. The concentration of molybdenum was found to be consistently $\sim 50 \%$ higher in the ordered particles than the matrix, and the concentration of nickel was consistently $\sim 10 \%$ lower in the ordered particles than in the matrix. The partitioning behavior of the chromium was found to vary among analyses, but was typically within $10 \%$ of being partitioned equally between the two phases. Segregation of chromium to the matrix-precipitate interface was also observed. Atom probe tomography also indicated strong partitioning behavior among minor and trace elements in these alloys. In particular, iron, manganese and aluminum were found to partition strongly to the matrix in these alloys.

Analyses in the vicinity of a grain boundary indicated substantial enrichment of Mo and $\mathrm{B}$ to the grain boundaries, consistent with the energy-filtered imaging results, and significant enrichment of the trace element phosphorous to the grain boundaries as well. The enrichment was not confined to the grain boundary plane, but had a width of a few nanometers.

Field ion microscopy images of these alloys showed brightly imaging atoms at the grain boundaries, indicative of boron segregation in agreement with the atom probe tomography results. Field ion images of the precipitates did not reveal the strong ring contrast at the low-index poles that are characteristic of ordered nickel-molybdenum phases. The poor contrast in these images suggests that these precipitates may not be fully ordered.

\section{ALCHEMI}

The site distributions of the major elements in the ordered $\mathrm{Ni}_{2}(\mathrm{Mo}, \mathrm{Cr})$ precipitates were characterized in the overaged alloy and an alloy with the two-step heat treatment (I-C) by the atom location by channeling enhanced microanalysis (ALCHEMI) technique.

Two ALCHEMI analyses of the overaged alloy were consistent with full ordering and the nominal sublattice distributions. Excellent discrimination between the two sublattices of the ordered particles was measured, and correlations of $99.5 \pm 3.4 \%$ and $98.6 \pm 1.9 \%$ in the variations of the molybdenum and chromium were measured. (A correlation of $100 \%$ indicates identical sublattice partitioning of two elements.)

Similar analyses of the ordered precipitates in alloy I-C indicated a lower degree of order in these alloys. Correlations of $72.7 \pm 16.0 \%$ and $73.1 \pm 9.4 \%$ in the variations of the molybdenum and chromium were measured. The lower values indicate that molybdenum is more distributed between the two sublattices than chromium, i.e., the chromium partitions more strongly to one sublattice than the molybdenum. The higher standard error in the measurement indicates that the two sublattices are not as strongly distinguished than in the overaged alloys, signifying that the particles are not fully 
ordered. These results are consistent with the poor ring contrast exhibited by the field ion images of the ordered particles.

\section{Mechanical testing}

Mechanical testing on all alloys was performed at Haynes International, Inc. Generally speaking, alloys exhibiting higher strength (yield strength and ultimate tensile strength) at temperature $T_{1}$ also exhibited lower ductilities (elongation to fracture) at $T_{1}$ and correspondingly higher hardness (Rockwell hardness) at room temperature. These tests for both heats I and II indicated that similar properties were exhibited by alloys receiving heat treating cycles $\mathrm{A}$ and $\mathrm{C}$. Alloys receiving heat treating cycle $\mathrm{B}$ exhibited substantially lower strength and higher ductilities, while alloys receiving heating cycle D exhibited modestly higher strengths and lower ductilities, than alloys receiving heat treating cycles $\mathrm{A}$ and $\mathrm{C}$. The overaged alloy exhibited the highest strength and hardness, and the lowest ductility, of all alloys tested.

\section{$\underline{\text { Inventions (Made or Reported) }}$}

No inventions are made or reported under this CRADA.

\section{Commercialization Possibilities}

The results of this CRADA have given the Participant a better understanding of HAYNES ${ }^{\circledR} 242^{\mathrm{TM}}$ and of how the proposed process revision affects the microstructure and interfacial segregation behavior in this alloy. The knowledge generated by this CRADA eliminates several strengthening mechanisms and will enable the Participant to explore possible experiments to help uncover the strengthening mechanisms in alloys fabricated using the two-step heat treatment. This CRADA has therefore brought the Participant a step closer to adopting the more energy-efficient two-step ageing treatment.

\section{$\underline{\text { Plans for Future Collaboration }}$}

The principle investigators for the Contractor and the Participant plan to publish the results of this CRADA in the open literature. This collaborative effort will help identify outstanding issues and possible follow-on experiments for this study. More generally, this collaboration has made the Participant aware of the microanalytical capabilities available through the contractor and the kind of knowledge that these capabilities can generate for the Participant. 


\section{$\underline{\text { Conclusions }}$}

Advanced characterization facilities at the ORNL SHaRE User Facility have revealed several microstructural and microchemical features of HAYNES® $242^{\mathrm{TM}}$ alloys that have been subjected to the currently used one-step heating cycle and a proposed alternative two-step heating cycle. All alloys have a primary microstructure of lenticular particles of nominal composition $\mathrm{Ni}_{2}(\mathrm{Mo}, \mathrm{Cr})$, with a monomodal size distribution, in a disordered $\mathrm{Ni}_{\mathrm{ss}}$ matrix. The ordered $\mathrm{Ni}_{2}(\mathrm{Mo}, \mathrm{Cr})$ particles are not highly ordered, but exhibit substantial distribution of the major elements between the two sublattices, although a high degree of order is achieved after long-term annealing in overaged alloys. All alloys exhibit segregation of molybdenum, boron and phosphorous to the grain boundaries.

The major microstructural difference between alloys processed with the current one-step and proposed alternative two-step heat treatment is the size of the particles. The lenticular particles are several times larger in alloys subjected to the two-step heat treatment relative to those in alloys with the one-step heat treatment. The larger particles form at the higher sub-solvus temperature during the first step of the two-step heat treatment. No secondary intragranular precipitates nucleate during the second step of the two-step heat treatment. The coarser microstructure may account for the lower strength and higher ductility of alloys subjected to the first stage of the two-step heat treatment relative to alloys subjected to the one-step heat treatment. However, the observed increase in strength and decrease in ductility following the second step of the two-step heat treatment, which results in mechanical properties similar to those of alloys subjected to the one-step heat treatment, does not result from the nucleation of finer secondary intragranular precipitates.

It is recommended that the properties observed in alloys subjected to the two-step heat treatment could be achieved with shorter ageing times than those used in the present study. 


\section{Distribution}

\section{Internal Distribution}

I. M. Anderson, 5500, 6376

R. A. Bradley, 4500S, 6161

E. E. Bloom, 4500S, 6132

R. D. Godfrey, 5500, 6376

D. R. Hamrin, 4500N, 6285

L. L. Horton, 4500S, 6132

G. W. Joe, 5002, 6416

Laboratory Records, 4500N, 6285 (2)

A. J. Luffman, 5002, 6416

M. K. Miller, 5500, 6376

T. L. Payne, 5002, 6416

T. M. Rosseel, 4500S, 6138

C. A. Valentine, 111UNV, 6499

\section{External Distribution}

D. L. Klarstrom, Haynes International, Inc., P.O. Box 9013, Kokomo, IN 46904-9013

L. M. Pike, Haynes International, Inc., P.O. Box 9013, Kokomo, IN 46904-9013

Office of Scientific and Technical Information, P.O. Box 62, Oak Ridge, TN 37831 (2)

Work for Others, DOE-ORO, ER-113, P.O. Box 2001, Oak Ridge, TN 37831

S. J. Barish, Department of Energy, SC-32, 19901 Germantown Rd., Germantown, MD 20874-1290

P. L. Gorman, DOE-ORO, ORNL Site Office, PO Box 2008, Oak Ridge, TN 37831-6269

W. M. Polansky, Department of Energy, SC-32, 19901 Germantown Rd., Germantown, MD 20874-1290 